\title{
Legal aspects of clinical ethics committees
}

Judith Hendrick Oxford Brookes University, Oxford

\begin{abstract}
In an increasingly litigious society where ritual demands for accountability and "taking responsibility" are now commonplace, it is not surprising that members of clinical ethics committees (CECs) are becoming more aware of their potential legal liability. Yet the vulnerability of committee members to legal action is difficult to assess with any certainty. This is because the CECs which have been set up in the UK are - if the American experience is followed - likely to vary significantly in terms of their functions, procedures, composition, structures and authority. As a consequence it is difficult to generalise about the legal implications. Nevertheless, despite these difficulties this article will outline the broad legal principles governing the potential liability of committee members. It will also consider the relationship between CECs and the courts. It begins, however, with a brief analysis of the relationship between ethics and law in committee deliberations, and in particular of the role of law and legal expertise on CECs.

(Fournal of Medical Ethics 2001;27 supp1 I:i50-i53)
\end{abstract}

Keywords: Clinical ethics committees; ethics; law; lawyers; courts; liability

The relationship between law and ethics To assert that law and ethics are interconnected is to state what is self evident and uncontroversial. Not only have they sprung from the same philosophical roots and Judaeo-Christian traditions, ${ }^{1}$ but they share the same vocabulary, in which terms such as rights, duties, responsibilities and obligations dominate, alongside concepts such as justice, fairness and equity. ${ }^{2}$ As Lord Chief Justice Coleridge stated over a century ago: "It would not be correct to say that every moral obligation involves a legal duty; but every legal duty is founded on a moral obligation". ${ }^{3}$ Both law and ethics are also normative and so aim to distinguish between acceptable and unacceptable behaviour by reflecting public opinion and current mores. ${ }^{4}$ Yet although law and ethics are related activities they are distinct. Thus the law is mandatory, setting minimum standards that can only be breached at the risk of civil or criminal liability. Accordingly, the questions asked when legal decisions have to be made are likely to be instrumental, such as: "What can we get away with?; Will we get sued if we do this?" Ethics, however, is aspirational, setting universal goals that we should try to meet but without there being penalties when we fall short. ${ }^{5}$ And whilst what is ethical is usually legal and vice versa, this is not always so since certain ethical principles are too vague to be translated into law or the law may be too blunt an instrument to enforce a moral idea. Telling lies, for example, is widely condemned as immoral yet there are very few laws against it. Note too that whilst the law has spoken clearly in many areas of bioethical concern-about death and dying, reproductive technologies, organ transplantation and so forth - in many areas there is no legal consensus and questions remain unresolved. That society should turn to the "magic" of the law and the legal system at a time of rapid technological advances in the belief that they can provide speedy, certain answers is, perhaps, not surprising. As Dworkin has observed, concern for medical ethics has often become a plea for medical law. ${ }^{6}$

What should be apparent, even from the above brief analysis, is that the relationship between law and ethics is a complex one. It is also controversial - or so it would seem from the very divergent views held as to the role of law in ethics discussions. ${ }^{7}$ Thus for some commentators law and legal expertise is very welcome, enriching and enhancing ethical analysis, particularly when applied to such legal concepts as informed consent, best interests and advance directives. The explicitly analogical nature of law and its clear articulation of distinctions among cases can likewise improve ethical analysis and study. ${ }^{8}$ Information about the law is useful too, in debunking legal myths and correcting misperceptions of the law. ${ }^{9}$ If these are not addressed, the most ethically desirable course of action may be ruled out on false legal grounds. Similarly, knowledge of the law can help physicians and others to understand what the real risks of civil or criminal liability are, and thus alleviate excessive fears. ${ }^{10}$ Identifying legal issues and in particular invoking the law to show whether an option recommended by a clinical ethics committee (CEC) is realistic, ie whether it can be implemented under current law, is another advantage which has been cited. Attention to legal criteria in decision making and legalised approaches are similarly said to foster deliberation and careful weighing of evidence as well as playing a fundamental role in tempering subjective discretion and minimising arbitrariness. ${ }^{.}$

For many legal scholars and ethicists, however, the law is more a menace than a friend and certainly a poor substitute for moral consensus. ${ }^{12}$ This is because legal intervention almost inevitably leads to "legalism"- a process Callahan ${ }^{13}$ describes as the translation of moral problems into legal problems; the inhibition of moral debate for fear that it will be so translated, and the elevation of the moral judgments of the courts as the moral standards of the land. Overemphasis on formal legal procedures 
and too narrow a focus on the law also inevitably, it is argued, reduce moral reasoning to mere rulefollowing. If this happens there is a danger of the focus shifting from what should be done morally to what needs to be done legally, with the consequence that CECs become little more than legal watchdogs whose only function is to promote adherence to law. ${ }^{14}$ Another of the law's sternest critics, Annas, ${ }^{15}$ claims that "good ethics committees begin where the law ends" and argues that setting up additional bureaucratic entities - or rather "risk management" or "liability control" committees as he prefers to call CECs - to make legal pronouncements can only make medicine more legalistic and impersonal. Using the law in ethics discussions also encourages committees to attempt to anticipate litigation behaviour and predict what a court might do-a practice which may directly conflict with what those consulting them believe to be the best outcome ethically. ${ }^{16}$ Finally there is the argument that an inappropriately placed legal comment can all too easily stifle ethical discussion. It has been suggested, for example, that "where there has been a lawyer on the ethics committee everybody looks to one end of the table where the lawyer sits and asks: 'What is the answer?' or 'Is that legal?' and the lawyer says: 'Yes, it's legal, it's fine,' or 'No, it isn't.' That, in some cases, will end the discussion." ${ }^{17}$ Whether this deference to the law is due to the tendency of lawyers to want to control proceedings and dominate discussion or is prompted by anxiety about potential legal responsibility is, of course, difficult to ascertain. But it is an important issue and a central concern for Bateman, ${ }^{18}$ who provides the most detailed analysis to date of the various roles lawyers have, if any, as members of CECs.

\section{The functions of CECs and the lawyer's role}

Although CECs have no standard mission, three main functions have been consistently identified in the literature, notably education, policy development and case review. ${ }^{19}$ Other functions less frequently cited include reducing litigation, ${ }^{20}$ helping to protect health care professionals legally by making them aware of any applicable law, ${ }^{21}$ and providing a forum for discussion of legal issues. Indeed it seems there is a common belief that CECs exist simply to provide legal assistance. ${ }^{22}$ But whatever the function there is widespread insistence that CECs are and should remain primarily advisory. Whilst this might be the intention, with little guidance about whom they are advising and in respect of what, there is likely to be confusion and this is where lawyers, trained to clarify issues, may be able to help.

Arguably the least controversial role for lawyers is in relation to a CEC's educative function. Here they can not only educate committee members about the law, dispelling common legal myths and explaining what the law allows but also contribute to seminars, lectures and other forums designed to educate hospital employees about legal and ethical aspects of treatment and so forth.

The second function, policy formulation, can take several different forms. Many committees actually make policies or draft policies for review by the hospital administration. Others may modify national guidelines, for example, on "do not resuscitate orders". ${ }^{23}$ But whatever the precise form policy development takes, lawyers, whose training teaches them to scrutinise words carefully, can be especially useful in playing "devil's advocate", alerting members to subtle ambiguities and uncertainties in the wording used and ensuring that a particular policy or set of guidelines is clear. ${ }^{24}$

\section{Wide variations}

The third function, case review, is the most problematic in terms of the lawyer's role not least because whilst much of the literature refers to some type of case analysis there are wide variations in the procedures adopted by committees, likewise what actually happens when they discuss cases. According to Bateman there are in practice four different approaches to resolving ethical issues through case analysis. As he notes, however, committees do not always consistently follow one specific approach and may even switch from one to another within the same case analysis. The most formal type of approach is the "case review". Issues which typically concern committees using this model are procedural, such as who can bring a case before the committee, who attends the review, who acts as the patient's advocate and who can vote. ${ }^{25}$ Given the legalistic nature of this approach-which is most pronounced if the review process is viewed as a potential substitute for the courts-it is not surprising that lawyers, who are familiar with quasi-judicial methodology, are best placed to ensure that proper procedures are followed and that the rights of patients and others are fully protected. "Case consultation" on the other hand is, as the name suggests, a much more consultative process. Like the "case review" scenario committees adopting this approach may reach decisions or make recommendations but will do so as specialists asked to consult on a difficult case. Their focus is thus on issues such as whether there is a need to see a patient or interview family members. In their deliberations they usually clarify what options exist (and the likely consequences of each).The lawyer's role here may be as an expert in the relationship between law and ethics and as an advisor on the legal ramifications of the various options discussed. The other two approaches, namely "case counselling" and "case discussion" will not be so dependent on a lawyer's special skills. In the former the concern is to "reshape the problem so that those facing the ethical dilemma can see appropriate solutions". ${ }^{26}$ Lawyers involved in this type of approach do not give legal advice or discuss legal implications of particular courses of action. Instead they can help clarify the issues - crucial if a consensus has to be reached but there are several issues, some of which may be obscure. In "case 
discussion", the intention is not to reach a decision or make a recommendation at all but to increase members' understanding. Lawyers contributing to this scenario are primarily likely to provide a legal perspective, for example, explaining how and perhaps why the law has developed as it has.

If Bateman's analysis of the lawyer's potential role is accepted it is clear that lawyers have much to contribute to a CEC. Nevertheless their participation has, as was noted above, been seriously challenged. Given too the ambivalence about the role of law in ethics discussions, it is almost inevitable that there is little consensus about the "proper" relationship between CECs and the courts.

\section{Clinical ethics committees and the courts}

The American experience reveals how almost every possible arrangement of courts and committees has been suggested. ${ }^{27}$ Thus some commentators have advocated case consultation as a way of trying to keep cases out of court. Others have argued that consultation should actually substitute for judicia review - an approach which is rejected unequivocally by Wolf not least because committees vary enormously, in ethical expertise, commitment to patient protection, and involvement of patients in the committee's processes. She also doubts that committees have the legal expertise, impartiality, commitment to precedent, or the public accountability to adjudicate legal rights. ${ }^{28}$ Given these divergent views it is not surprising that American judges have also failed to be consistent in their approach. Thus in one case ${ }^{29}$ the courts treated a committee's determinations as highly persuasive "evidence" in so far as they used its documentation both to illuminate the process followed in arriving at the decision and to validate the decision. In other words the court seemed to use the committee's documentation for assurance that the doctor and experts had come up with the right answer, and that the appropriate procedure would yield that answer. ${ }^{30}$ But in other cases the courts have virtually ignored a committee's recommendations ${ }^{31}$ or have ordered some kind of future committee process. ${ }^{32}$ Nor is the position in the UK any clearer. This is because no court has yet considered an ethics committee's recommendation. What legal authority it would ascribe to such a recommendation in the future is therefore uncertain. Nevertheless in view of the UK courts' traditional deference to the medical profession, it is unlikely that they would seriously challenge a CEC's decision-unless of course, it failed to comply with a responsible body of medical opinion. ${ }^{33}$ It is also probable that the courts would endorse a CEC's interpretation (and modification) of national guidelines, for example, those issued by the BMA concerning "do not resuscitate orders". ${ }^{34}$ Again, however, this would be subject to any modification conforming to accepted practice. ${ }^{35}$ However, the issue of adherence to guidelines raises another important aspect, notably the risk of CEC members being sued for the ethics advice they give.

\section{Legal liability of CEC members}

A decade ago it was commonly, if not universally, believed that ethicists and other members of CECs, were unlikely to be legally liable when conducting clinical ethics consultations. ${ }^{36}$ However, concerns about liability are now being taken far more seriously, with one commentator suggesting it is only a matter of time until a CEC is held liable for a bad outcome; in short an "ethics disaster" is waiting to happen. ${ }^{37}$ It is, of course, difficult to draw generalities about the potential legal liability of CECs, given the wide variety of functions they perform (ie education, formulating policy and guidelines, and review of cases). Nevertheless it is widely agreed that the clearest potential for legal responsibility-for ethicists and other CEC members performing consultative services-lies in giving prospective advice concerning the treatment of a particular patient. In other words, committees acting as advisory bodies offering recommendations may be liable for the advice they give. ${ }^{38}$ Should any action be taken, however, it would almost certainly be a negligence claim, in which it would be alleged that there was a failure to exercise due care in giving advice or making a recommendation, and the patient suffered injury as a result. ${ }^{39}$

To succeed in such a claim, four conditions would need to be present. Briefly these are: first a duty of care must be established. For some writers there is no doubt that such a duty is owed to any patient who is the subject of consultation. ${ }^{40}$ Others are less convinced. Merritt, for example, ${ }^{41}$ notes that in some circumstances it is arguable that the duty of care is owed to the doctor asking the committee's advice rather than the patient in question. Accordingly the courts are only likely to recognise that committees owe a duty of care to patients when they consult the committee directly or when the committee otherwise purports to act in their best interests. Similarly debated in the literature is the second condition in a negligence claim, namely breach of the required standard of care. In the absence of a Bolam test in this context (likewise any standards of accreditation, licensing or formal guidelines governing CECs) there has been much speculation as to the skills a court might expect of an ethicist and other committee members. Nevertheless the most "fundamental" which have been suggested include an ability: to identify and analyse clinical ethical problems; to use and model reasonable clinical judgment; to communicate with and educate team, patient and family; to negotiate and facilitate negotiations, and to teach and assist in problem resolution. ${ }^{42}$ The third condition, ie that the claimant has suffered injury, may not present too much of a hurdle for the victim of the alleged negligence but it still has to be established and would require medical evidence. But the fourth condition, that the negligence of committee members is both the legal and proximate cause is certainly problematic. The widely accepted test for cause which works in most but not all cases is known as the "but for" test. That is that the defendant's breach of duty is the cause of the 
damage if that damage would not have occurred "but for" the defendant's behaviour. Hence, if the victim can show that the doctor would more likely not have acted as he or she did if the committee's advice had been otherwise, then its advice could be said to be the cause of the injuries. The difficulty here, however, would be proving this causal link when the precise authority of the CEC and how its consultation service was categorised may be very flexible or uncertain. As DuVal notes, a CEC can be mandatory or optional, both as to whether cases are brought before it and as to whether its determinations are binding on the clinical team. Only in cases where a CEC had the power to dictate the appropriate course of action would the causal link be clearly established. ${ }^{43}$ In others, such as those in which the doctor could ignore the committee's advice, the legal position is much less clear.

\section{Conclusion}

This article has outlined the legal aspects of CECs which have most often been discussed in the literature and are typically regarded as the most controversial. But it is by no means comprehensive. It does not address issues such as indemnity for committee members; how they can ensure that any guidelines or policy they formulate are lawful, and that procedures and processes comply with the principles of natural justice. Its failure to do so, however, will hopefully not deter those considering becoming committee members in the future nor hasten the resignation of those already in place. As Weir has remarked: "We would all be gutless wonders if we didn't realise that there are worse things than being sued". ${ }^{44}$

Fudith Hendrick, BA, LLM, is a Solicitor, and a Senior Lecturer in Law at Oxford Brookes University, Oxford.

\section{References}

1 Bauman S. Clinical ethics: what's law got to do with it? Archives of Family Medicine 1999;8:345-6.

2 Hendrick J. Law and ethics in nursing and health care. Cheltenham: Stanley Thornes, 2000.

3 In R v Instan[ [1893] 1 QB at 453.

4 Stone J, Matthews J. Complementary medicine and the law. Oxford: Oxford University Press, 1996.

5 Annas G. Ethics committees: from ethical comfort to ethica cover. Hastings Center Report 1999;21:18-21.

6 Dworkin RB. Limits: the role of law in bioethical decision making. Bloomington: Indiana University Press, 1996.

7 Hoffman DE. Does legislating hospital ethics committees make a difference? A study of hospital ethics committees in Maryland, the District of Columbia, and Virginia Law, Medicine and Health Care 1991;19:105-19.

8 Spielman B. Invoking the law in ethics consultation. Cambridge Quarterly of Healthcare Ethics 1993;2:457-67.

9 Fletcher JC. The bioethics movement and hospital ethics committees. Maryland Law Review 1991;50:859-94.

10 Cranford RJ, Jackson. Neurologists and the hospital ethics committee. Four seminars in neurology, cited in Merritt AL.
The tort liability of hospital ethics committees. Southern Californian Law Review 1987;60:1239-97.

11 Spielman B. Organizational ethics programs and the law. Cambridge Quarterly of Healthcare Ethics 2000;9:218-29.

12 See reference 11 , footnote 3 for details of commentators who have described CECs as too legalistic.

13 Callahan D. Escaping from legalism: is it possible? Hastings Center Report 1996;26:34-5.

14 Weir RF. Paediatric ethics committees: ethical advisers or legal watchdogs? Law, Medicine \& Health Care 1987; 15: 99-110.

15 See reference 5: 21

16 See reference 8: 463 .

17 Cohen M, Hartz J, Schwartz R, Shapiro R. Everything you always wanted to ask a lawyer about ethics committees. Cambridge Quarterly of Healthcare Ethics 1992;1:33-9.

18 Bateman RB. Attorneys on bioethics committees: unwelcome menace or valuable asset? Fournal of Law and Health 1994; 9:247-72.

19 Slowther A, Hope T, Bunch C. Clinical ethics committees in the UK. Fournal of the Royal College of Physicians of London 1999;33:202-3. See also Hoffman DE. Evaluating ethics committees: a view from outside. The Milbank Quarterly 1993; 71: 677-701

20 Gillon R. Clinical ethics committees-pros and cons. Fournal of Medical Ethics 1997;23:203-4.

21 Jaffe GA. Institutional ethics committees: legitimate and impartial review of ethical health care decisions. The fournal of Legal Medicine 1989;10:393-431.

22 See reference $7: 119$

23 Larcher V. Role of clinical ethics committees. Archives of Disease in Childhood 1999;81:104-6.

24 See reference 18: 265 .

25 See reference $18: 255-9$

26 See reference 18: 258

27 For a general discussion of the relationship between ethics committees and the courts see Wolf SM. Towards a theory of process. Law, Medicine and Healthcare 1992; 20: 78-90 and see also reference 21: 421

28 See refere $21: 421$.

29 In re Torres, 357 NW2d 332 (Minn 1984).

30 Wolf SM. Ethics committees in the courts. Hastings Center Report 1986;16:12-15

31 Fleetwood J, Unger SS. Institutional ethics committees and the shield of immunity. Annals of Internal Medicine 1994;120:320-5.

32 See reference 27: 279

33 See Bolam v Friern Hospital Management Committee [1957] 2 All ER 118 but note also effect of Bolitho v City of Hackney HA [1998] AC 232.

34 British Medical Association. Cardiopulmonary resuscitation-a statement from the BMA and RCN. London: BMA,1999.

35 As they did in Re R (adult: medical treatment) [1996] 2 FLR 99. See also the courts' acceptance of BMA guidelines on PVS patients in Airedale NHS Trust v Bland [1993] 1 All ER 821. For further discussion of the legal status of clinical guidelines see Hurwitz B. Clinical guidelines and the law. Abingdon: Radcliffe Medical Press, 1998.

36 Staubach SM. What legal protection should a hospital provide, if any to its ethics committee and individual members? HEC Forum 1989;1:209-20 but contrast Self D, Skeel J. Legal liability and clinical ethics consultations. In: Monagle J, Thomasma DC, eds. Medical ethics: a guide for health professionals. Rockville: DC, eds. Medical ethics: a guide for hea

37 Leeman CP, Fletcher J, Spencer E, Fry-Revere, S. Quality control for hospitals' clinical ethics services: proposed standards. Cambridge Quarterly of Healthcare Ethics 1997;6:257-68.

38 Merritt AL. The tort liability of hospital ethics committees. Southern Californian Law Review 1987;60:1239-97.

39 DuVal G. Liability of ethics consultants: a case analysis. Cambridge Quarterly of Healthcare Ethics 1997;6:269-81.

40 See reference 39: 272.

41 See reference 38: 1297.

42 See reference 39: 273.

43 See reference 39: 276 .

44 See reference 14: 109 . 